\title{
Michał Suchanek
}

Chair of Economics and Management of Transport Companies, Faculty of Economics, University of Gdańsk, Poland

\section{THE COSTS OF RETROFITTING SMART TACHOGRAPHS IN HDVS IN EUROPEAN UNION}

\begin{abstract}
The paper focuses on the costs connected with the idea of retrofitting smart tachographs in all heavy duty vehicles in the European Union. Such a motion has been proposed, in order to increase the road safety. The new class of tachographs, ie. the smart tachographs are supposed to be fitted with a GNSS device ensuring a constant monitoring of the vehicle's speed and other parameters but also a transmitter which should allow to send data in real time without the necessity to download the data manually. However, such a vast process will generate severe costs for the Member States' administration but also for private companies which will need to handle the cost of fitting the device in their vehicles. The purpose of the article is to estimate this cost.
\end{abstract}

Keywords: transport economics, smart tachographs, European Policy

\section{Introduction}

The need to measure and control basic parameters of driver's activity led to an EU-wide introduction of obligatory tachograph, a device fitted into the vehicle which records data such as: the distance covered by the vehicle, current speed and periods of driver's labour and rest. The tachograph in general consists of three parts: a sender unit, the tachograph head, and a recording medium. The tachographs are currently fitted in newly registered vehicles carrying goods with permissible mass of over 3.5 tonnes and vehicles (buses) carrying more than 9 passengers.

So far, the vehicles have been fitted with either analogue tachographs (before 2006) or one of the three generations of digital tachographs. The analogue tachographs collected the data on a wax coated paper disc which showed the activity of the vehicle within a 24-hour period. The focus was put on the record of speed 
and driving time. However, these tachographs were easily tampered with the use of very simple devices which switched them off or disturbed the record. This is why digital tachographs were then introduced. So far, there have been three generations of digital tachographs, differing in software versions, the type of required motion sensors and additional safety mechanisms such as a second independent signal (Herma, 2015). he introduction of these innovations was supposed to make it impossible to harness the recording of the tachograph thus ensuring that it fulfills its purpose. The fact of the matter is that, while it may have improved the road safety it also led to a number of new techniques which allow to interfere with the signaling and the recording, including devices for remote disabling of the motion sensor, using a masked switch or remote controls (Rychter, 2011).

The authorities of the European Union has thus come to a conclusion that the digital tachographs do not provide a needed level of safety and a new idea is needed (Commission Regulation, 2009), which led to the concept of "smart tachographs" fitted with a GNSS module and allowing to automatically record the location and displacement of the vehicle. The motion sensor in these vehicles is supposed to be enclosed in a secure box and the signal itself is secured between GNSS receiver and vehicle unit (VU), while the satellite signal is authenticated. The smart tachographs include a DSRC module which allow the enforcers to collect data such as (Martinez, 2017):

- latest security breach attempts;

- longest power supply interruption;

- sensor faults;

- motion data errors;

- vehicle motion conflict;

- invalid card, card insertion while driving;

- calibration data;

- vehicle registration number;

- speed.

The European Commission discusses the possibility of retrofitting smart tachographs in all heavy duty vehicles in the European Union by the end of 2020 as proven by Regulation EU 2016/799 (European Commission, 2016). While this is an interesting motion from the point of view road safety, it is bound to generate vast costs for the transport companies and authorities.

\section{Vehicles subject to tachograph retrofitting}

Currently, the digital tachographs are fitted in newly registered commercial vehicles with a maximum permissible mass of more than 3.5 tonnes and buses or coaches carrying more than nine persons. The Regulation (EU) 165/2014 foresees fitting of a new generation of smart tachographs in all newly registered vehicles of this type from 1st June 2019 onwards.

In order to calculate the cost of retrofitting the smart tachographs in the EU, first the number of vehicles subject to retrofitting has to be established. This can be done 
using a linear regression prognosis based on the available Eurostat data on the total number of commercial vehicles and the number of light commercial vehicles which are not subject to retrofitting. Each of those vehicles which are subject to the process will generate a cost connected with retrofitting which will consist of two main parts: the cost of the device itself (the tachograph) and the cost of labour connected with the service of retrofitting performed. in a licensed workshop. The smart tachograph itself is not yet available on the market so the prices are based on current market estimates. The cost of labour can be based on the current service of retrofitting connected with the digital tachographs but it has to be weighted by the cost of labour in different countries. It is assumed that the costs of retrofitting will not differ depending on the current generation of used tachograph due to the fact that regardless of the generation, the whole device will have to be replaced. The light commercial vehicles (with maximum permissible mass of less than 3.5 tonnes), which account for over $80 \%$ of all the commercial vehicles are out of scope of the current legislation and therefore not taken into consideration in this analysis. On estimate, by 2020 , there will be $32.5 \mathrm{mln}$ light commercial vehicles, as their number has been growing since 2011. In consequence, by subtracting the number of light commercial vehicles from the number of all commercial vehicles, it can de deduced that by 2020 , there will be over 7 million vehicles which have to be retrofitted with a smart tachograph (Suchanek, 2018).

Table 1. Number of vehicles subject to tachograph retrofitting - projection for 2020

\begin{tabular}{|c|c|}
\hline Country & $2020 \mathrm{P}$ \\
\hline Austria & 75763 \\
\hline Belgium & 151895 \\
\hline Bulgaria & 128247 \\
\hline Croatia & 60892 \\
\hline Czech Republic & 229907 \\
\hline Denmark & 46855 \\
\hline Estonia & 43875 \\
\hline Finland & 106205 \\
\hline France & 655900 \\
\hline Germany & 989007 \\
\hline Greece & 259943 \\
\hline Hungary & 103830 \\
\hline Ireland & 51674 \\
\hline Italy & 906383 \\
\hline Latvia & 35476 \\
\hline Lithuania & 64566 \\
\hline Luxembourg & 13134 \\
\hline Netherlands & 143493 \\
\hline Poland & 1274216 \\
\hline Portugal & 117260 \\
\hline Romania & 300343 \\
\hline Slovakia & 97305 \\
\hline
\end{tabular}


Table 1. cont.

\begin{tabular}{|l|c|}
\hline \multicolumn{1}{|c|}{ Country } & $2020 \mathrm{P}$ \\
\hline Slovenia & 38066 \\
\hline Spain & 529227 \\
\hline Sweden & 92873 \\
\hline United Kingdom & 686392 \\
\hline EU & 7202727 \\
\hline
\end{tabular}

Source: (Suchanek, 2018)

Each of these vehicles will generate a retrofitting cost for their corresponding enterprise which will consist of the cost of the smart tachograph itself. It will be approximately constant across the EU. Secondly, another cost generated to the road transport enterprises will be the cost of labour connected with the service of fitting, calibrating and testing the tachograph in a workshop. The labour cost is variable across the EU and will result in a different cost of retrofitting. The annual data on labour costs are used to calculate a coefficient for the discounted weighted labour cost. The labour cost of fitting and calibrating and testing one smart tachometer in a vehicle has been estimated for Poland at 96 EUR (Kordel, Waśkiewicz, 2013; Gil, Ignaciuk, 2014). Poland estimation of the cost is taken as the basis as it is the country with the biggest estimate fleet of vehicles subject to retrofitting by 2020 .

\section{The estimation of the retrofitting cost}

The estimated cost of fitting and authorising of a smart tachometer in the EU is prone to be discounted for larger enterprises and has to be adjusted for the labour cost in particular countries. The EU road transport fleet distribution structure is characterized by a relative dominance of small companies which own about $58 \%$ of all the fleet, therefore it can be estimated that $42 \%$ of vehicles (EU cross-border transport companies with a large fleet i.e. with over 10 vehicles) could be serviced at a discounted rate estimated for the purpose of this calculation at 15\% (Goyal, Gunasekaran, 1992; George, Xia, 2011). This in turn means that the average base labour cost of fitting a tachograph should be discounted for the whole fleet of vehicles to 89.95 EUR. This base cost will vary in different countries due to a different labour cost. Due to the fact, that the smart tachograph is not yet in production, there is no market price to refer to. Different sources provide different estimated market prices ranging from 675 EUR (Wieteska, Piechota, 2016) through 800 EUR (a 33.3\% increase from the current price of the digital tachograph) up to 2000 EUR (A maximum increase of the market price, based on inquiries with producers suggesting that the smart tachograph will include a much more specialised equipment than current digital tachographs including GNSS receiver and will therefore have a proportionately higher price) (Suchanek, 2018).

The cost of retrofitting the tachographs in all subject vehicles by 2020 varies depending on the price variant chosen and ranges from 6.4 bn EUR through 
7.3 bn EUR to 15.9 bn EUR. The estimated costs of retrofitting depending on the variant of the price are presented in the table 2 .

Table 2. Cost of retrofitting the smart tachographs depending on the market price

\begin{tabular}{|c|c|}
\hline Estimated market price of the tachograph & Estimated cost of retrofitting (in EUR) \\
\hline 675 EUR & 6381503188.83 \\
\hline 800 EUR & 7281844104.14 \\
\hline 2000 EUR & 15925116891.18 \\
\hline
\end{tabular}

Source: (Suchanek, 2018)

Regardless of the chosen variant of the price, the three countries in which the highest costs will be generated are: Poland, Germany and Italy as they have relatively the biggest vehicle fleets. In the case of the lowest estimated price (675 EUR) Germany will be the country in which the highest cost will occur due to a relatively higher cost of labour. However, if the price of the device increases, the relative share of the labour cost decreases and therefore the countries with the lower costs of labour increase their share of the overall cost. In the case of both the medium (800 EUR) and the high (2000 EUR) price of the device, the country in which the highest cost will occur is Poland. This cost will in general be harder to bare for the smaller enterprises which cannot expect any discounts due to generally smaller fleet sizes and lower market strength resulting in lack of negotiation power (Suchanek, 2018).

\section{Conclusions}

The retrofitting of smart tachographs in all subject vehicles by 2020 is an extensive process and will certainly generate significant costs for the main actors of the European transport market. The main cost will be incurred to the transport enterprises, which will be the cost of purchasing the devices and the cost of labour connected with the service of retrofitting. This cost will on estimate amount to between 6.4 and 15.9 bn EUR depending on the real market price of the tachograph. The smart tachographs are not yet available on the market so different price variants ranging from 675 to 2000 EUR have been assumed in these estimations. It is worth mentioning that the process of retrofitting the smart tachographs will mostly affect these Member States in which the largest number of vehicles participate in the European transport market, that is Poland, Germany, Italy, United Kingdom, France and the Netherlands. This changes will mostly be a burden for the micro and small transport enterprises which operate using a small fleet of vehicles as they will not be able to negotiate and take benefit from discounts on services of retrofitting possible for the enterprises with larger fleets. 


\section{References}

Commission Regulation (2009) (EU) No 1266/2009 of 16 December 2009 adapting for the tenth time to technical progress Council Regulation (EEC) No 3821/85 on recording equipment in road transport (Text with EEA relevance).

European Commission (2016). Commission Staff Working Document, Ex-post evaluation of the social legislation in road transport: Regulation (EC) No 561/2006 on driving times, breaks and rest periods of drivers, Directive 2002/15/EC on the working time of road transport mobile workers and directive 2006/22/EC on enforcement requirements.

George, D.K. and Xia, C.H. (2011), Fleet-sizing and service availability for a vehicle rental system via closed queueing networks, European Journal of Operational Research, 211.

Gil, L. and Ignaciuk, P. (2014), Wpływ odległości transportowych na koszty transportu. Autobusy, 5.

Goyal, S.K. and Gunasekaran, A. (1992), Determining economic maintenance frequency of a transport fleet, International Journal of Systems Science, 23

Herma, M. (2015), Manipulations in digital tachographs, WIP, Warszawa.

Kordel, Z. and Waśkiewicz, J. (2013), Problems of costs and prices in the road transport, Zeszyty Naukowe. Problemy Transportu i Logistyki, 21.

Martinez, B. (2017), Smart tachograph. Road Transport Unit (DG MOVE. Available from http://ec.europa.eu/transparency/regexpert/index.cfm?do=groupDetail.groupDetailDoc\&id $=27716 \&$ no $=5$ [Accessed 11 January 2018]

Rychter, F. (2011), Level of implementation of digital tachograph system in Europe in light of introduction of digital tachograph second generation, Transport Problems, 6.

Suchanek, M. (2018), Retrofitting smart tachographs by 2020: Costs and benefits, European Parliament Think Tank.

Wieteska, S. and Piechota, A. (2016), Modern Management Methods for Truck and Van Fleets in Poland, Acta Scientifica Academiae Ostroviensis, 8.

\section{Corresponding author}

Michał Suchanek can be contacted at: ekomsu@ug.edu.pl 